Loyalitas Kreativitas
Aldi Masyarakat Kreatif

P-ISSN 2722-2101, E-ISSN 2722-4201

Program Studi Ekonomi Manajemen Universitas Pamulang

Jurnal LOKABMAS Kreatif Vol. 01, No. 01, Hal. 63 - 70

Email:jurnalkreatif.manajemen@gmail.com

\title{
PELATIHAN AUDIT INTERNAL DANA BOS
}

\author{
Nurmono, S.E.,M.M. ${ }^{1)}$, Dede hendra, S.E, M.M. ${ }^{2)}$, Dewi Nari Ratih Permada, S.E.,M.M. ${ }^{3)}$ \\ Drs.Gatut Dradjad Purwoko,M.M. ${ }^{4)}$, Sulistiyani, ${ }^{5)}$ \\ Dosen Manajemen Fakultas Ekonomi Universitas Pamulang \\ Email: ${ }^{1)}$ dosen02254@ unpam.ac.id; ; ${ }^{3)}$ dosen00821@ unpam.ac.id , \\ dosen00612@unpam.ac.id
}

\begin{abstract}
ABSTRAK
Kegiatan pegabdian kepada masyarakat ini bertujuan untuk mensosialisasikan dan memberikan penyuluhan terkait pengetahuan bagaimana cara Audit Internal Dana BOS, sehingga bisa memaksimalkan dana tersebut sesuai dengan tujuan dan sasarannya.

Pelaksanaan kegiatan Pengabdian Kepada Masyarakat oleh Lembaga Penelitian dan Pengabdian Masyarakat (LPPM) Universitas Pamulang yang dilakukan oleh dosen-dosen program studi Manajemen telah berjalan dengan lancar dan mendapat sambutan hangat dari tempat pelaksanaan kegiatan ini yaitu Kepala SMP N 04 Tangerang Selatan. Harapan kami dengan pengabdian ini dapat menambah ilmu yang bermanfaat dalam hal audit internal dana BOS.

Hasil kegiatan menunjukkan bahwa sebelum pelaksanaan pelatihan, para peserta dari sekolah sudah mengenal sebagian istilah audit dan dana BOS, tetapi mereka hanya mengetahui jenis-jenis yang umumnya saja. Namun setelah pelaksaan kegiatan diketahui para peserta perwakilan dari sekolah tersebut dapat memahami dari mulai dasar-dasar sampai cara mengaudit dana BOS dengan benar.
\end{abstract}

\section{Kata kunci : Audit, Dana BOS}

\section{ABSTRACT}

This community service activity aims to socialize and provide counseling related to knowledge on how to conduct Internal Audit of BOS Funds, so that they can maximize the funds in accordance with their goals and objectives.

The implementation of Community Service Activities by the Pamulang University Research and Community Service Institute (LPPM) conducted by lecturers in the Management Study Program has been running smoothly and received a warm welcome from the venue for this activity, namely the Principal of SMP N 04 South Tangerang. We hope that this dedication can add useful knowledge in the internal audit of BOS funds.

The results of the activity showed that prior to the training, participants from the school were already familiar with some of the terms of the audit and BOS funds, but they only knew the general types. However, after the implementation of the activity it was found out that the representatives of the school could understand from the basics to how to audit BOS funds properly.

Keywords: Audit, BOS Funds

\section{A. PENDAHULUAN}

Undang-undang Nomor 20 Tahun 2003 tentang Sistem Pendidikan Nasional pasal 6 mengamanatkan bahwa setiap warga negara yang berusia 7-15 tahun wajib mengikuti pendidikan dasar. Pasal 34 ayat 2 menyatakan bahwa Pemerintah dan Pemerintah Daerah menjamin terselenggaranya wajib belajar minimal 
pada jenjang pendidikan dasar tanpa memungut biaya. Pasal 34 ayat 3 menyatakan bahwa wajib belajar merupakan tanggungjawab Negara yang diselenggarakan oleh lembaga pendidikan Pemerintah, Pemerintah Daerah dan Masyarakat. Konsekuensi dari amanat tersebut adalah Pemerintah berkewajiban memberikan layanan pendidikan dan membiayai pelaksanaan program pendidikan, bagi peserta didik pada tingkat Sekolah Dasar (SD) dan Sekolah Menengah Pertama (SMP) serta satuan pendidikan lain yang sederajat.

Dalam rangka melaksanakan amanat tersebut serta mendukung pencapaian program penuntasan Wajib Belajar Pendidikan Dasar Sembilan Tahun (Wajar 9 Tahun), sampai saat ini pemerintah masih dihadapkan pada berbagai permasalahan. Permasalahan tersebut antara lain belum optimalnya pemerataan kesempatan pendidikan, rendahnya kualitas pendidikan, maupun terbatasnya anggaran yang tersedia untuk penyelenggaraan pendidikan. Terkait dengan terbatasnya anggaran pendidikan, kenaikan harga Bahan Bakar Minyak (BBM) yang diikuti dengan turunnya nilai tukar rupiah US dolar menimbulkan kenaikan harga kebutuhan pokok, seperti sandang, pangan, perumahan, dan kesehatan. Permasalahan tersebut secara langsung maupun tidak langsung berpengaruh negatif terhadap kemampuan masyarakat untuk mengakses layanan pendidikan.

Selama ini pemerintah selalu berusaha memecahkan masalah pemerataan pendidikan. Salah satu upaya untuk meningkatkan akses masyarakat terhadap pendidikan bermutu, yang mendapat alokasi anggaran cukup besar adalah program Bantuan Operasional Sekolah atau dikenal dengan BOS. BOS merupakan suatu program pemerintah untuk membantu penyediaan pendanaan biaya operasional nonpersonalia sekolah. Program Bantuan Operasional Sekolah dikomandani oleh Departemen Pendidikan Nasional, yang mana dalam pelaksanaannya, penyaluran dan pengelolaan dana BOS wajib berpedoman pada Buku Petunjuk Teknis Penggunaan dana BOS yang diterbitkan oleh Departemen Pendidikan Nasional dan Departemen Agama sebagai departemen teknis yang bertanggungjawab dalam pelaksanaan dan pengelolaan program BOS (Mulyono,2010:170).

Jumlah dana BOS yang diberikan kepada sekolah dihitung berdasarkan jumlah murid di masing-masing sekolah. Adapun besaran dana BOS untuk jenjang Sekolah Dasar tahun 2011 masing-masing Rp 400.000 per siswa per tahun di kota, dan sebesar Rp 397.000 per siswa per tahun untuk di Kabupaten. Sedang untuk jenjang Sekolah Menengah Pertama sebesar Rp 575.000 per siswa per tahun di kota, dan Rp 570.000 per siswa per tahun di Kabupaten (Depdiknas, 2010). Jika pada tahun 2010, penyaluran dana BOS mengikuti skema APBN yang disalurkan dari propinsi langsung ke sekolah, untuk tahun 2011 berubah menjadi mekanisme transfer ke daerah (Kabupaten/Kota) dalam bentuk dana penyesuaian untuk BOS sebagaimana tercantum dalam Undang-Undang Nomor 10 Tahun 2010.

Berdasarkan buku Petunjuk Teknis (Juknis) BOS, dana BOS digunakan untuk mendanai biaya operasional nonpersonalia, seperti biaya untuk bahan atau peralatan pendidikan habis pakai, dan biaya tidak langsung berupa daya, air, jasa telekomunikasi, pemeliharaan sarana prasarana, uang lembur, transportasi, konsumsi, pajak, asuransi, dan lain-lain. Dalam penggunaan dana BOS tersebut, dana diprioritaskan untuk kebutuhan biaya operasional nonpersonalia, bukan biaya untuk investasi dan bukan biaya untuk kesejahteraan guru. Walaupun pada pelaksanaannya, ada beberapa jenis pembiayaan investasi dan personalia yang boleh dibiayai menggunakan dana BOS.

Keuangan sekolah perlu dikelola dengan baik. Pengelolaan keuangan sekolah penting untuk dilakukan agar dana yang diperoleh dapat digunakan secara efektif dan efisien. Pengelolaan 
keuangan sekolah yang baik dapat dilakukan dengan menggunakan: asas pemisahan tugas, perencanaan, pembukuan setiap transaksi, pelaporan dan pengawasan. Namun, hasil penelitian Suparjio (2000: hal 5) menyatakan bahwa dalam pengelolaan keuangan di Sekolah Dasar, yang menjadi hambatan adalah masih minimnya rutinitas pembukuan setiap transaksi dan ketidaksesuaian antara perencanaan dengan pelaksanaan dan laporan keuangan sekolah. Berdasarkan hasil penelitian dilapangan tersebut, dapat diambil kesimpulan bahwa kemampuan sekolah dalam mengelola keuangan sekolah dapat dikatakan belum optimal.

Dana BOS yang diberikan untuk sekolah juga perlu dikelola dengan baik. Salah satu faktor yang mempengaruhi keberhasilan program BOS adalah pengelolaan dana dan segala sumberdaya yang ada dalam program BOS. Pentingnya pengelolaan dana BOS yaitu, dengan pengelolaan yang baik akan mampu membantu ketercapaian tujuan dari program BOS dengan efektif dan efisien. Pengelolaan dana BOS yang baik merupakan suatu keberhasilan sekolah dalam mengelola dana BOS, melalui suatu proses kerjasama yang sistematis mulai dari perencanaan, pelaksanaan, sampai dengan evaluasi.

Untuk itu, kami Dosen Universitas Pamulang dan mahasiswa mengadakan Pengabdian Kepada Masyarakat (PKM) bekerjasama dengan SMP N 04 Tangerang Selatan untuk memberikan pelatihan kepada guru di gugus 04 dengan judul "Pelatihan Audit Internal Dana BOS".

\section{B. METODE}

PELAKSANAAN KEGIATAN

Metode kegiatan ini berupa pemberian tips dan trik kepada para peserta. Berikut ini adalah tahapan pelatihan yang dilakukan:

1. Tahap persiapan, Tahap persiapan yang dilakukan meliputi:

a. Survey awal,

b. Pemantapan dan penentuan lokasi dan sasaran. Setelah survey maka ditentukan lokasi pelaksanaan dan sasaran peserta kegiatan.
2. Tahap Pelaksanaan Pengabdian Kepada Masyarakat

Tahap ini akan diberikan penjelasan mengenai apa itu Audit Internal dana Bos. Sesi ini menitik beratkan pada pemberian penjelasan mengenai bagaimana penerapan audit internal.

2. Tahap Pelatihan

Untuk melaksanakan kegiatan tersebut digunakan beberapa metode pelatihan yaitu:
a. Metode ceramah
b. Metode tanya jawab
c. Metode simulasi

\section{HASIL DAN PEMBAHASAN}

\section{Tahap Persiapan}

Sebelum melaksanakan Pengabdian Kepada Masyarakat kami selaku Dosen Universitas Pamulang melakukan prasurvey kepada beberapa sekolah di wilayah Tangerang selatan. Berdasarkan data dan informasi yang kami dapatkan bahwa penerapan audit internal dan BOS masih belum terlaksana dengan baik.

Hal ini menuntut para stakeholder sekolah untuk memahami mengenai pentingny audit internal laporan keuangan pengunaan dana BOS. Oleh karena itu, kami Dosen Universitas Pamulang melakukan pertemuan dengan SMP N 04 Tangerang Selatan untuk memberikan solusi terhadap permasalahan mengenai audit internal dana BOS.

Setelah itu, TIM PKM yang terdiri dari lima orang Dosen UNPAM melakukan Forum Group Discussion (FGD) untuk mempersiapkan pelaksanaan Pengabdian Kepada Masyarakat (PKM) untuk tanggal di Kelurahan SMP N 04 Tangerang Selatan.

2. Tahap Pelaksanaan Pengabdian Kepada Masyarakat

Pelaksanaan Pengabdian

Kepada Masyarakat di Lembaga Pemberdayaan Masyarakat pada tanggal 10 - 12 Desember 2019. Kegiatan dilaksanakan di Aula SMP N 04 Tangerang Selatan. Kegiatan ini 
terlaksana atas kerjasama Universitas Pamulang dengan SMP N 04 Tangerang Selatan. dengan tema " PELATIHAN AUDIT INTERNAL DANA BOS". Kegiatan ini di ketua oleh Nurmono S.E., M.M.. dengan narasumber Bapak Gatut drajat Purwoko dan dibantu dosen UNPAM lainnya yaitu Dede Hendra, S.E., M.M., Dewi Nari Ratih Permada, S.E., M.M., Sulistiyani, S.Pd., M.Pd., . Kegiatan PKM ini dihadiri kebanyakan dari kalangan guru.

\section{Tahap Pelatihan}

Untuk melaksanakan kegiatan tersebut digunakan beberapa metode pelatihan yaitu:

a. Metode ceramah

Metode yang digunakan dalam pelatihan SDM dimulai dengan memberikan ceramah atau presentasi dengan tema " AUDIT INTERNAL DANA BOS", dengan narasumber Gatut drajat Purwoko yang dibantu oleh Dede Hendra, S.E., M.M. sebagai moderator.

b. Metode tanya jawab

Setelah sesi ceramah sudah selesai, maka dilanjutkan dengan sesi tanya jawab. Alhamdulillah peserta sangat antusias untuk menanyakan bagaimana cara Ausit internal dana BOS bisa berjalan dengan baik. Peserta yang bertanya kami berikan cendremata dari Universitas Pamulang dan sumbangsih dari dosen-dosen UNPAM.

c. Metode simulasi

Pelatihan ini juga diberikan metode simulasi, sehingga peserta langsung dapat mempraktekan apa yang sudah disampaikan. Apabila ada kendala maka langsung dibantu pada saat pelaksanaan PKM. Simulasi penting dilakukan untuk mengetahui seberapa besar tingkat pengetahuan dan ilmu yang diserap pada saat pelatihan.

\section{KESIMPULAN DAN SARAN}

\section{Kesimpulan}

Pelaksanaan

kegiatan

Pengabdian Kepada Masyarakat oleh Lembaga Penelitian dan Pengabdian Masyarakat (LPPM) Universitas Pamulang yang dilakukan oleh dosendosen program studi Manajemen telah berjalan dengan lancar dan mendapat sambutan hangat dari tempat pelaksanaan kegiatan ini yaitu Kepala SMP N 04 Tangerang Selatan. Harapan kami dengan pengabdian ini dapat menambah ilmu yang bermanfaat dalam hal audit internal dana BOS.

Dalam laporan kegiatan ini mungkin banyak kekurangan yang ada, untuk itu kami berharap masukan dan kritikan dalam rangka perbaikan untuk kegiatan-kegiatan pengabdian masyarakat di masa yang akan datang. Semoga kegiatan pengabdian masyarakat ini dapat bermanfaat bagi masyarakat sekitar lingkungan Universitas Pamulang dan lainnya.

Akhirnya, kami mengucapkan terima kasih kepada seluruh pihak yang telah mendukung kegiatan yang kami laksanakan dan kami mohon maaf apabila dalam laporan ini banyak ditemukan kekurangan.

\section{Saran}

Berdasarkan hasil kegiatan Pengabdian Kepada Masyarakat, maka kami dari Tim Dosen Universitas Pamulang memberikan saran diantaranya sebagai berikut:

a. Untuk pihak sekolah dan seluruh jajaran stakeholder untuk lebih mengedepankan prinsip-prinsip akuntabilitas dalam proses laporan keuangan yang nantinya akan mempermudah proses audit dan agar proses audit dijalankan sesuai prinsip prinsip audit yang telah dijelaskan dalam materi pelatihan..

b. Adanya kontribusi dari pihak universitas untuk bisa memberikan fasilitas dalam pelayanan kepada 
masyarakat dalam bentuk sarana dan prasarana.

\section{E. DAFTAR PUSTAKA}

Amrizal. 2004. Pencegahan dan Pendeteksian Kecurangan oleh Internal Auditor. Diklat bpkp.

Arens, A. A., Elder R. J., \& Beasley, M. S. 2008. "Auditing dan Jasa Assurance Pendekatan Terintegrasi”. Jakarta: Erlangga.

Cahyo, M. N., \& Sulhani. 2017. "Analisis Empiris Pengaruh Karakteristik Komite Audit, Karakteristik Internal Audit, Whistleblowing System, Pengungkapan Kecurangan Terhadap Reaksi Pasar". Jurnal Dinamika Akuntansi dan Bisnis, Vol.4 No. 2.

Sawyer, B., 2012, Sawyer's Internal Audit, , Buku 2 Salemba Empat, Jakarta.
Pasaribu, V. L. D., Agrasadya, A., Shabrina, N., \& Krisnaldy, K. (2020). MENJADI ENTERPRENEUR MUDA YANG MEMILIKI JIWA LEADERSHIP UNTUK MENGHADAPI MASA DEPAN. Abdi Laksana, 1(1)

Pasaribu, V. L. D., Elburdah, R. P., Sudarso, E., \& Fauziah, G. (2020). PENGGUNAAN MANAJEMEN WAKTU TERHADAP PENINGKATAN PRESTASI BELAJAR DI SMP ARAISIYAH. Jurnal ABDIMAS, 1(1)

Pasaribu, V. L. D., Susanti, F., \& Hartuti, E. T. K. (2019). MEMOTIVASI SISWA DAN SISWI SMK LETRIS INDONESIA DI DALAM MENENTUKAN PILIHAN UNTUK MELANJUTKAN PENDIDIKAN ATAU BEKERJA SETELAH LULUS SEKOLAH. Jurnal Pengabdian Dharma Laksana, 1(2), 161-172. 